\title{
Potential Prospect of CDK4/6 Inhibitors in Triple-Negative Breast Cancer
}

\author{
Ye Hu (D) \\ Jiyue Gao \\ Meiling Wang (D) \\ Man Li
}

Department of Oncology \& Department of Breast Surgery, The Second Hospital of Dalian Medical University, Dalian, People's Republic of China
Correspondence: Man Li

Department of Oncology \& Department of Breast Surgery, The Second Hospital of Dalian Medical University, Dalian, People's Republic of China

Tel +86-4| I-8467|29|

Fax +86-4II-8467II230

Email man_li@dmu.edu.cn

\begin{abstract}
Triple-negative breast cancer (TNBC) is an aggressive, difficult-to-treat subtype of cancer with a poor prognosis; there is an urgent need for effective, targeted molecular therapies. The cyclin D/cyclin-dependent kinase (CDK)4/6-retinoblastoma protein ( $\mathrm{Rb}$ ) pathway plays a critical role in regulating cell cycle checkpoints, a process which is often disrupted in cancer cells. Selective CDK4/6 inhibitors can prevent retinoblastoma protein phosphorylation by invoking cell cycle arrest in the first growth phase (G1), and may therefore represent an effective treatment option. In this article, we review the molecular mechanisms and therapeutic efficacy of CDK4/6 inhibitors in combination with other targeted therapies for the treatment of triple-negative breast cancer. Three selective CDK4/ 6 inhibitors have so far received the approval of the Food and Drug Administration (FDA) for patients with estrogen receptor (ER)+/human epidermal growth factor receptor 2 (HER2) breast cancer. Trilaciclib, a small molecule short-acting inhibitor of CDK4/6, has also been approved recently for people with small cell lung cancer, and is also expected to be clinically effective against breast cancer. Although the efficacy of CDK4/6 inhibitors in patients with triple-negative breast cancer remains uncertain, their use in conjunction with other targeted therapies may improve outcomes and is therefore currently being explored. Identifying biomarkers for response or resistance to $\mathrm{CDK} 4 / 6$ inhibitor treatment may optimize the personalization of treatment strategies for this disease. Ongoing and future clinical trials and biomarker studies will shed further light on these topics, and help to realize the full potential of CDK4/6 inhibitor treatment in triple-negative breast cancer.
\end{abstract}

Keywords: triple-negative breast cancer, palbociclib, biomarkers, combination therapy

\section{Introduction}

Breast cancer is one of the most common types of cancer worldwide, with approximately 2.3 million new cases and 685,000 deaths in 2020. ${ }^{1}$ Three types of breast cancer are currently recognized, based on histology: hormone receptor positive (HR + ), human epidermal growth factor receptor-2 overexpressing (HER2+) and triplenegative breast cancer (TNBC). ${ }^{2}$ People with triple-negative breast cancer (TNBC) account for between $15 \%$ and $20 \%$ of all breast cancer cases. However, the prognosis of this subtype is poor owing to a lack of effective therapeutic options. ${ }^{3}$ The most common first-line clinical treatment strategy for TNBC patients is adjuvant chemotherapy, and cancer progression occurs in $20-40 \%$ patients with early-stage disease who receive this treatment.

There is little variation in the approach to clinical treatment in people with TNBC; however, there are different biologic subgroups of this disease, so a more personalized approach may improve outcomes. In a US study, Lehmann et al found 
that TNBC is a highly diverse heterogeneous breast cancer, and proposed a classification system comprising seven subtypes based on gene expression profiles; ${ }^{4}$ in another study, Jiang et al classified TNBC into four transcriptomebased subtypes: luminal androgen receptor (LAR), mesenchymal (MES), mesenchymal stem like (MSL), and basal-like (BL). ${ }^{5}$ Distinguishing between subtypes could hopefully improve clinical outcomes of this disease in the near future by enabling health professionals to select more effective targeted therapeutics based on the molecular profile of each type. ${ }^{6,7}$ This strategy is being put into practice: atezolizumab is FDA-approved in combination with paclitaxel protein-bound for patients with advanced TNBC whose tumors express programmed death ligand 1 (PD-L1) (PDL1 stained tumor-infiltrating immune cells [IC] of any intensity covering $\geq 1 \%$ of the tumor area). Olaparib is also FDA-approved for the treatment of patients with germline breast cancer susceptibility gene (BRCA)-mutated, HER2-negative metastatic breast cancer who have received chemotherapy either in the neoadjuvant, adjuvant, or metastatic setting. Both of these drugs have showed good clinical efficacy against the breast cancer subtypes for which they have been approved. ${ }^{8-10}$ Therefore, identifying new biomarkers and drug targets for TNBC is a high clinical priority.

The mitotic cell cycle is a complex process and requires the tightly coordinated action of its components and continuous activation of several cyclin-CDK complexes. ${ }^{9}$ Dysregulation of cellular proliferation is a feature of all human cancers, and the maintenance of abnormal proliferative signals is a key marker for cancer. ${ }^{11}$ The cell-cycle regulatory proteins CDK4 and CDK6 were identified in the early 1990s, and therapies targeting these proteins have since been developed, based on a large body of research demonstrating that overactivity of the cyclin D-CDK4/6 axis leads to excessive proliferation in tumor cells. ${ }^{12,13}$ CDK4/6 kinases and associated cyclin D proteins are involved in the cell cycle transition from the first growth (G1) to the DNA synthesis (S) phase. The CDK4/6-cyclin D1 complex mediates phosphorylation of retinoblastoma protein $(\mathrm{pRb})$, which then releases inhibition of E2F and other transcription factors, which then initiate DNA replication and promote cellular transition into $\mathrm{S}$ phase. ${ }^{14,15}$ This axis also connects cell proliferation to several other signaling pathways (Figure 1). People with HR-positive breast cancer, in particular, may benefit from therapy with CDK4/6 inhibitors, as the function of $\mathrm{Rb}$ is intact in this subtype; ${ }^{16}$ however, the lack of specific biomarkers and target genes in TNBC makes predicting the efficacy of CDK4/6 inhibitors in this subtype difficult.

In this review, we summarize our current knowledge of the molecular mechanisms of action and drug resistance in CDK4/6 inhibitor treatment, focusing on research into new biomarkers that may provide a theoretical basis for expanding the use of CDK4/6 inhibitors in TNBC. We also explore new therapeutic strategies aiming to effectively target this aggressive subtype of breast cancer.

\section{The Role of CDK4/6 in Cell Cycle Control and the Molecular Mechanism for CDK 4/6 Inhibitor Action}

Cell-cycle checkpoints sustain mitotic cell cycle progression, controlling the timing of transitions between the four phases: G1, S, G2, and mitosis (M). ${ }^{11}$ The CDK family of serine/threonine kinases regulates these transitions in combination with associated cyclins. ${ }^{17}$ In general, the cyclin family of proteins is diverse, and its members are classed as A, B, D, or E-type cyclins. ${ }^{18}$ Specific CDK-D cyclin pairs operate during different phases of the cell cycle. D-type cyclins include three subtypes, which vary according to the tissue context: D1, D2, and D3. ${ }^{19}$ In the early stages of the cell cycle, growth factor receptor activation leads to increased levels of D-type cyclins, which provides the initial mitogenic signal. Cyclin D and CDK4/6 subunits form a complex, which is then phosphorylated by CDKactivating kinase (CAK) after entering the nucleus. ${ }^{20}$ These activated complexes in turn phosphorylate $\mathrm{Rb}$ and pocket proteins p107 and p130 (also known as $\mathrm{RbL} 1$ and RbL2). Phosphorylation of the $\mathrm{Rb}$ protein releases inhibition of the transcription factor E2F, which and induces cyclin $\mathrm{E}$ expression. Cyclin $\mathrm{E}-$ CDK2 complexes promote further phosphorylation of $\mathrm{Rb}$, which drives the cell into $\mathrm{S}$ phase and initiates DNA replication. ${ }^{21-23}$ Loss of control over this checkpoint in cell proliferation often occurs in cancer cells; hypo-phosphorylated $\mathrm{Rb}$ results in cell cycle arrest, and CDK-dependent hyperphosphorylation of $\mathrm{Rb}$ results in the loss of the tumor suppressive function of $\mathrm{Rb}^{24}$ The initial phosphorylation events that lead to $\mathrm{Rb}$ phosphorylation $(\mathrm{pRb})$ are usually dependent on accumulation of cyclin D-CDK4/6 complexes in the G1 phase (Figure 1). Consequently, through activation of cyclin 


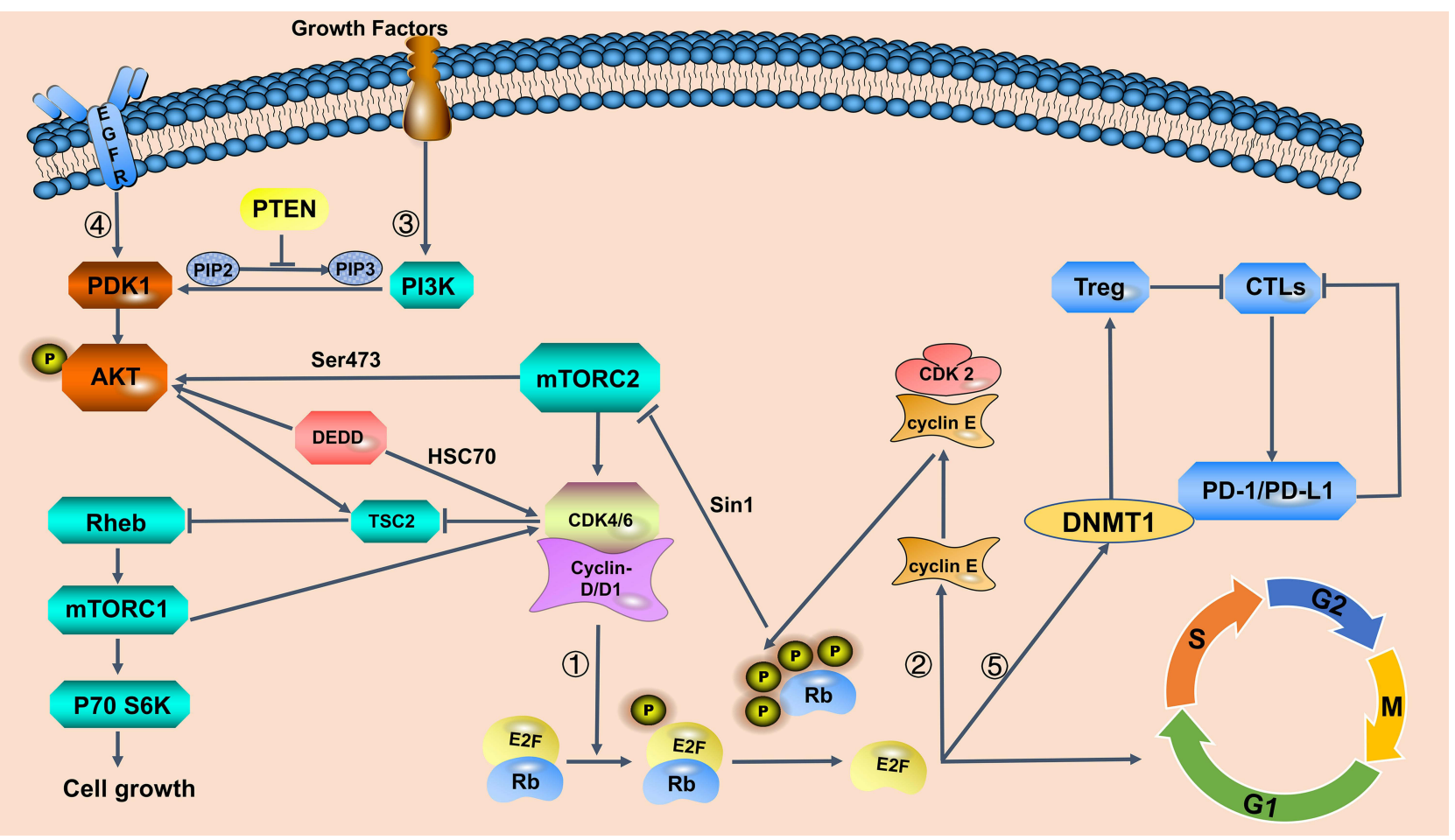

Figure I Interaction of the cyclin-dependent kinase (CDK)4/6 pathway with other signaling pathways in breast cancer.

Notes: (1) Cyclin D-CDK4/6 complexes induce retinoblastoma $(\mathrm{Rb})$ phosphorylation, which in turn releases suppression of the E2F transcription factor, triggering the transition from the first growth (GI) to DNA synthesis (S) phase of the cell cycle. Loss of Rb results in resistance to CDK4/6 inhibitors. (2) Phosphorylation of Rb activates cyclin E, which in turn binds to CDK2; positive feedback promotes Rb phosphorylation and, along with the action of CDK4/6 complexes, drives mitotic cell division. (3) Phosphoinositide 3-kinase (PI3K) pathway increases cyclin DI levels and inhibits tuberous sclerosis complex 2 (TSC2) phosphorylation, thereby maintaining GTP-bound state of ras homolog enriched in brain (Rehb) and enhancing mammalian rapamycin complex I (mTORCI) activity. Phosphorylated Rb binds to Sin I and suppresses the activation of mTORC2, which promotes protein kinase B (AKT) phosphorylation. Synergistic inhibition of the PI3K/AKT/mechanistic target of rapamycin (mTOR) and CDK4/6 pathway can reduce cyclin DI levels and release the inhibition of TSC2 phosphorylation, thus enhancing the inhibition of $m$ TORCI and blocking cell entry into the $\mathrm{S}$ phase. Collectively, reducing Rb phosphorylation promotes AKT pathway activity, which may result in CDK4/6 inhibitor resistance. The combination of CDK4/6 and PI3K/ AKT/mTOR inhibitors effectively blocks these pathways. (4) Cyclin D-CDK4/6 inhibition synergizes with epidermal growth factor receptor (EGFR) inhibition. EGFR inhibitors effectively inhibit PAKT transiently, but cancer cells consistently sustain AKT signaling via the death-effector domain containing protein (DEDD)-dependent pathway. DEDD interacts with heat shock cognate 70 (HSC70) to stabilize cyclin DI, which is a critical component of the GI to S phase regulatory complex. (5) A target gene of E2F, DNA (cytosine-5) methyltransferase I (DNMTI), decreases the suppression of cytotoxic T lymphocytes (CTLs) which are inhibited by regulatory T lymphocyte cells. CTLs kill cancer cells by producing programmed cell death protein I (PD-I). CDK4/6 inhibitors improve protein stability of PD ligand I (PD-LI), which renders PD-I inactive.

$\mathrm{D}-\mathrm{CDK} 4 / 6$ or loss of $\mathrm{Rb}$, tumor cells can circumvent restriction at the $\mathrm{G} 1 / \mathrm{S}$ checkpoint through $\mathrm{pRb}$ dependent growth suppression. ${ }^{25,26}$ Conversely, CDK4/ 6 inhibitors can inhibit the proliferation of these tumor cells by blocking cyclin D-CDK4/6-dependent $\mathrm{Rb}$ phosphorylation.

The cyclin D-CDK4/6-INK4-Rb-E2F axis is mainly involved in the regulation of cell cycle transition and the enzyme activity of $\mathrm{CDK} 4 / 6$ is regulated by multiple mechanisms. Cyclin-CDK complex activity is blocked by CDK-inhibitors (CKIs) which are comprised of two families, INK4 family (p16, p15, p18, and p19) and CDK interacting protein/Kinase inhibitory protein (CIP/KIP) family (p21, p27). ${ }^{27,28}$ INK4 family proteins are characterized by multiple ankyrin repeats, and act mainly to decrease the catalytic activity of CDK4 and CDK6. The CIP/KIP proteins inhibit a broader spectrum of cyclin-CDK complexes, thus leading to cell cycle arrest during the G1 phase. Loss-of-function of p16Ink4a, encoded by $C D K N 2 A$, occurs frequently in many types of cancer. Importantly, research has revealed that loss-of-function of p16Ink4a leads to greater sensitivity to CDK4/6 inhibitors. ${ }^{16}$ This may be related to rapid upregulation of CDK2 activity in $C D K N 2 A$ loss tumors after exposure to CDK4/6 inhibitors, thus maintaining $\mathrm{Rb}$ phosphorylation and cell cycle progression during the G1 phase. $^{29}$ Moreover, in resting (interphase) cells, CDK2 is inactive and CDK2 complexes are suppressed by $\mathrm{p} 21$ and p27 (Figure 1). ${ }^{30-32}$ Dysregulation of cyclinD-CDK4/6-INK4-Rb-E2F axis in the tumor cell cycle is associated with many malignancies, which supports CDK4/6 as an attractive anticancer therapeutic target. 


\section{Clinical Applications of CDK4/6} Inhibitors

Flavopiridol was the first broad-spectrum CDK inhibitor to successfully enter clinical trials. These studies revealed that this drug significantly inhibited all CDKs (CDK1, 2, 4 , and 7) in vitro, and cell cycle progression was blocked at G1/S and G2/M boundaries. ${ }^{33}$ However, the efficacy of this first-generation broad-spectrum $\mathrm{CDK}$ inhibitor was limited, and treatment was associated with unacceptable adverse effects, including myelosuppression, gastrointestinal toxicity, and severe neutropenia. ${ }^{34-37}$ The discovery and cloning of cyclin-dependent kinases (CDKs) enabled researchers to design new $\mathrm{CDK}$ activity regulators, including dinaciclib, a second-generation CDK inhibitor with greater selectivity than flavopiridol. However, in some clinical trials, severe adverse toxic effects of this drug were also observed.

A new generation of oral CDK inhibitors has greater selectivity than first- and second-generation CDK inhibitors. ${ }^{38}$ For example, palbociclib (PD0332991), a specific inhibitor of CDK4/6, has been shown to effectively inhibit the proliferation of retinoblastoma $(\mathrm{Rb})$ positive tumor cells in vitro, resulting in cell cycle arrest in the G1 phase, accompanied by reduced phosphorylation of $\mathrm{Rb}$ at Serine (Ser)780/Ser795. Selective inhibitors of cyclin-CDK4/6 generally have improved safety profiles owing to reduced off-target effects. ${ }^{39}$

Currently, there are three FDA-approved CDK4/6 inhibitors: palbociclib, ribociclib, and abemaciclib. In 2015, palbociclib received FDA approval as a standard first-line therapy to treat postmenopausal women with ER+/HER2advanced breast cancer in combination with endocrine therapy following the PALOMA-1 clinical trial. ${ }^{40}$ Ribociclib was preliminarily approved in the same population in March 2017 after positive results in MONALEESA-2. ${ }^{41}$ Following the MONARCH-1 and MONARCH-2 clinical trials, abemaciclib received approval from FDA as a monotherapy for patients with ER+/HER2 - advanced breast cancer in people whose disease had progressed despite endocrine therapy and chemotherapy, ${ }^{42}$ or in combination with fulvestrant in patients with HR+/HER2 - advanced breast cancer, with disease progression following endocrine therapy. ${ }^{43}$

Progression-free survival was shown to improve significantly in clinical trials of these drugs, doubling with palbociclib or ribociclib combined with letrozole (a therapeutic agent for postmenopausal women with breast cancer) compared with letrozole alone. ${ }^{40,41,44}$ Palbociclib or abemaciclib in combination with fulvestrant as a second-line treatment substantially extended progression-free survival in breast cancer patients with progression after treatment with aromatase inhibitors. ${ }^{43,45}$ The encouraging results from these randomized clinical trials of combination therapies support further research to explore novel combination therapies in other subtypes of breast cancer.

\section{CDK 4/6 Inhibitors in TNBC}

TNBC is negative for ER, progesterone receptor (PR), and HER2. ${ }^{46,47}$ TNBC is a relatively heterogeneous and highly aggressive cancer; there is therefore an urgent need to identify molecular targets that could be therapeutically targeted. ${ }^{48,49}$ Importantly, TNBC has a very poor prognosis with higher rates of early distant metastatic compared with other subtypes of breast cancer. ${ }^{47,50}$ Genomic and clinical data have shown low $\mathrm{Rb}$ expression levels and Cyclin E1 amplification, a high frequency of TP53 mutations, and increased CDKN2A expression. ${ }^{51,52}$ Owing to the frequent loss of $\mathrm{Rb}$ in TNBC, the efficacy of $\mathrm{CDK}$ inhibitors in these patients is not well understood. However, some results from preclinical studies suggest that TNBC is sensitive to CDK inhibitor treatment. The identification of TNBC biomarkers may reveal other targets for molecular therapies in TNBC. ${ }^{53}$ The identification of biomarkers may also help to identify which patients may respond well to CDK4/6 inhibitor therapy. Extensive studies have suggested that combination therapies may help to overcome drug resistance by targeting multiple signaling pathways in TNBC. Table 1 summarizes the promising combination therapy regimens discussed in this article.

\section{Sensitivity to CDK4/6 Inhibitors in TNBC}

According to The Cancer Genome Atlas (TCGA), loss or mutation of $\mathrm{Rb} 1$ occurs in $20 \%$ of people with TNBC. ${ }^{51}$ In a previous study, CDK4/6 inhibitors were shown to effectively suppress TNBC cell proliferation with expression of $\mathrm{Rb}$ protein; surprisingly, this suppression was not dependent on ER or HER2 status. ${ }^{54}$ The authors assessed the sensitivity of a wide range of cells to abemaciclib. In this study, the response to these drugs was observed among 560 human cancer cells with $\mathrm{Rb}+$ tumor cells. These findings supported the idea that loss-of-function $\mathrm{Rb}$ mutations lead to CDK4/6 inhibitor resistance, ${ }^{29,55}$ and that $\mathrm{Rb}$ may predict whether cells are sensitive to CDK4/6 inhibitors. ${ }^{56,57} \mathrm{Rb}$ loss may lead to increased expression 
Table I Potential Combination Therapy Strategies for Triple-Negative Breast Cancer

\begin{tabular}{|c|c|c|c|}
\hline Combinations & Regimens & Target & Indications \\
\hline CDK4/6 inhibitors & $\begin{array}{l}\text { Palbociclib/Abemaciclib/ } \\
\text { Ribociclib }\end{array}$ & The cyclin D-CDK4/6-INK4-Rb-E2F axis & $\mathrm{Rb}+\mathrm{TNBC}$ \\
\hline $\begin{array}{l}\text { CDK4/6 inhibitors+CyclinE/ } \\
\text { CDK2 inhibitors }\end{array}$ & $\begin{array}{l}\text { Palbociclib+Cyclin E/CDK2 } \\
\text { inhibitors }\end{array}$ & Cyclin E-CDK2 axis & $\begin{array}{l}\text { High expression level of CDK2 } \\
\text { or Cyclin E TNBC }\end{array}$ \\
\hline $\begin{array}{l}\text { CDK4/6 inhibitors } \\
\text { +Autophagy inhibitors }\end{array}$ & $\begin{array}{l}\text { Palbociclib/Abemaciclib+ HCQ } \\
\text { Palbociclib+ CQ/Lys } 05 / \\
\text { Bafilomycin AI }\end{array}$ & $\begin{array}{l}\text { The cyclin D-CDK4/6-INK4-Rb-E2F axis + } \\
\text { Autophagy }\end{array}$ & $\mathrm{Rb}+/ \mathrm{LMWE}-\mathrm{TNBC}$ \\
\hline $\begin{array}{l}\text { CDK4/6 inhibitors }+A R \\
\text { inhibitors }\end{array}$ & Palbociclib+ Enzalutamide & $\begin{array}{l}\text { The cyclin D-CDK4/6-INK4-Rb-E2F axis } \\
\text { (GI arrest) } \\
\text { Mechanism is unclear }\end{array}$ & $A R+T N B C$ \\
\hline $\begin{array}{l}\text { CDK } 4 / 6 \text { inhibitors }+\mathrm{PI} 3 \mathrm{~K} \\
\text { inhibitors }\end{array}$ & $\begin{array}{l}\text { Palbociclib+ BYL7I9/BEZ235/ } \\
\text { BKMI20 }\end{array}$ & $\begin{array}{l}\text { The cyclin D-CDK4/6-INK4-Rb-E2F axis } \\
\text { +PI3K/AKT/mTOR pathway }\end{array}$ & PIK3CA mutation TNBC \\
\hline $\begin{array}{l}\text { CDK } 4 / 6 \text { inhibitors +Dual- } \\
\text { mTOR inhibitors }\end{array}$ & Palbociclib+ MLNOI28 & $\begin{array}{l}\text { The cyclin D-CDK4/6-INK4-Rb-E2F axis } \\
\text { +PI3K/AKT/mTOR }\end{array}$ & $\mathrm{Rb}+\mathrm{TNBC}$ \\
\hline $\begin{array}{l}\text { CDK } 4 / 6 \text { inhibitors }+\mathrm{AKT} \\
\text { inhibitors }\end{array}$ & $\begin{array}{l}\text { Palbociclib/Ribociclib+ } \\
\text { MK2206/GDC0068 }\end{array}$ & $\begin{array}{l}\text { The cyclin D-CDK4/6-INK4-Rb-E2F axis } \\
\text { +PI3K/AKT/mTOR pathway }\end{array}$ & PTEN-deficiency TNBC \\
\hline $\begin{array}{l}\text { CDK4/6 inhibitors } \\
\text { +Immune-checkpoint } \\
\text { inhibitors }\end{array}$ & $\begin{array}{l}\text { Palbociclib/Ribociclib+ Anti-PD } \\
\text {-I/PD-LI immunotherapy }\end{array}$ & $\begin{array}{l}\text { The cyclin D-CDK4/6-INK4-Rb-E2F axis + } \\
\text { PD-LI protein }\end{array}$ & $\begin{array}{l}\text { Higher infiltration of TILs/High } \\
\text { expression of PD-LI TNBC }\end{array}$ \\
\hline $\begin{array}{l}\text { CDK } 4 / 6 \text { inhibitors +Anti- } \\
\text { EGFR inhibitors }\end{array}$ & Palbociclib+ Erlotinib & $\begin{array}{l}\text { The cyclin D-CDK4/6-INK4-Rb-E2F axis + } \\
\text { MT4-MMP/EGFR signaling pathway }\end{array}$ & $\begin{array}{l}\text { Co-expressing of MT4-MMP, } \\
\text { EGFR and Rb TNBC }\end{array}$ \\
\hline $\begin{array}{l}\text { CDK } 4 / 6 \text { inhibitors +Anti- } \\
\text { EGFR inhibitors }\end{array}$ & Palbociclib+ Lapatinib & $\begin{array}{l}\text { The cyclin D-CDK4/6-INK4-Rb-E2F axis } \\
\text { +EGFR/HER2 signaling pathway }\end{array}$ & $\begin{array}{l}\text { EGFR+/DEDD over-expression } \\
\text { TNBC }\end{array}$ \\
\hline $\begin{array}{l}\text { CDK4/6 inhibitors } \\
+ \text { Chemotherapy }\end{array}$ & Palbociclib+ Paclitaxel & $\begin{array}{l}\text { The cyclin D-CDK4/6-INK4-Rb-E2F axis + } \\
\text { Glucose uptake and consumption }\end{array}$ & TNBC \\
\hline
\end{tabular}

Notes: Autophagy inhibitors: chloroquine (CQ), hydroxychloroquine (HCQ), Lys05, bafilomycin AI; PI3K inhibitors: BYL7I9; BEZ235; BMKI20; Dual-mTOR inhibitors: MLNOI28; AKT inhibitors: MK2206; GDC0068.

Abbreviations: LMWE, cytoplasmic staining of cyclin E; MT4-MMP, membrane-type-4 Matrix metalloproteinase; EGFR, epidermal growth factor receptor; TILs, tumorinfiltrating lymphocytes.

of p16ink4a, and these changes may occur simultaneously. Loss of p16ink4a function as a tumor suppressor may confer high sensitivity to CDK4/6 inhibitors. The reasons for $\mathrm{Rb}$ loss and mechanisms of p16ink4a overexpression are unclear, but p16ink $4 \mathrm{a}$ and $\mathrm{Rb}$ could be important biomarkers to predict response to CDK4/6 inhibition in TNBC. $^{58,59}$

\section{CDK4/6 Inhibitors in Combination with Cyclin E or CDK2 Inhibition}

TCGA analysis has revealed that $85 \%$ of breast cancers are $\mathrm{Rb}+$ with low cyclin E expression. ${ }^{60}$ Research has shown that CDK2 and cyclin $\mathrm{E}$ affect the activity of CDK4/6; Rb phosphorylation can also occur through the CDK2 as well as the CDK4/6 pathway. ${ }^{56,61}$ Briefly, after Rb phosphorylation, the expression of E2F target genes, including E-type cyclins, increases. Cyclin E then activates CDK2, forming a cyclin E-CDK2 complex, which promotes Rb phosphorylation (Figure 1). The progression from $\mathrm{G} 1$ to $\mathrm{S}$ phase continues via the activation of the cyclin E-CDK2 axis. Hence, inhibitors of cyclin E/CDK2 in combination with CDK4/6 inhibitors may expand the group of patients that could benefit from this type of therapy. ${ }^{62-64}$

To explore whether CDK4/6 inhibitors could be used to treat different molecular subtypes of TNBC, a study that measured CDK4/6 activity in Rb1 wild-type TNBC cell lines revealed that the proliferation of LAR subtype tumor cells was effectively inhibited by palbociclib in vitro and in vivo using a MDAMB453-derived xenograft model. Palbociclib-sensitive LAR TNBC cells usually enter 
a dormant low-CDK2 state, where CDK4/6 phosphorylation of $\mathrm{Rb} 1$ protein is required to cross the critical point for cell cycle progression to continue. Conversely, the resistance of basal-like TNBC cells to palbociclib therapy owes to the proliferative high-CDK2 state. This result revealed that cells with the high-CDK2 phenotype entered a proliferative state after mitosis, bypassing checkpoint. Tumors with a high CDK2 expression level were generally found to be resistant to CDK4/6 inhibitors. ${ }^{53}$ In palbociclib-resistant cancer cells, abnormal expression of cyclin E1 was observed after mitosis, resulting in a high-CDK2 phenotype; the cyclin E-CDK2 complex thus becomes active promptly after mitosis, leading to shortening of the G1 phase. Furthermore, in 2009, a new CDK inhibitor, PHA-848125, was shown to highly selectively inhibit CDK2 and reduce the expression of P21Cip1, p27Kip1. These proteins have been reported to inhibit the state of CDK2 activity after mitosis. ${ }^{65}$ These results may lay the theoretical foundation for CDK2 and cyclin E inhibitors in combination with CDK4/6 inhibitors as a novel therapeutic strategy worth considering for people with TNBC. ${ }^{53}$ More research is therefore required to evaluate the potential therapeutic efficacy of this strategy.

\section{CDK4/6 Inhibitors in Combination with Autophagic Inhibition}

Autophagy is a stress tolerance mechanism in cancer, which promotes the degradation of cell components by fusing cell components with lysosomes and provides energy for survival. ${ }^{66}$ Autophagy is an important drug resistance mechanism that occurs with many cancertargeting agents, including palbociclib, which has been shown to induce reactive oxygen species (ROS)-mediated senescence and autophagy. ${ }^{67,68}$ Targeting autophagic mechanisms may therefore represent another approach to therapy. One study evaluated the effect of CDK4/6 inhibitors in combination with inhibitors of autophagy on seven TNBC cell lines with different expression levels of $\mathrm{Rb}$ and cytoplasmic staining of cyclin E (LMWE). Rb+/LMWEcell lines, and tumors in a xenograft mouse model derived from these cells, were found to be more sensitive to this combination therapy. CDK4/6 inhibitors activate autophagy; blocking autophagy may therefore distinctly improve the G1/S blocking effect mediated by CDK4/6 inhibitors. ${ }^{60}$ These results also suggest that $\mathrm{Rb}$ and cyclin E may be useful biomarkers for TNBC prognosis, and may help to identify where autophagy inhibitors could be used to enhance the effect of Palbociclib.

\section{CDK4/6 Inhibitors in Combination with Androgen Receptor (AR) Inhibition by Enzalutamide}

$\mathrm{AR}$ expression is a well-known prognostic marker in breast cancer; $20-40 \%$ of patients with TNBC are AR $+{ }^{69-73}$ Enzalutamide is currently approved by FDA to treat people with metastatic prostate cancer. $^{74,75}$ A preclinical study demonstrated that ER-/AR + cell lines proliferate in an AR-dependent manner, which is suppressed by AR inhibitors; AR may therefore represent a therapeutic target for breast cancer. ${ }^{76}$ Liu et al revealed that LAR TNBC cell lines were highly sensitive to CDK4/ 6 inhibitors; a recent study that tested palbociclib and enzalutamide in $\mathrm{AR}+/ \mathrm{Rb}+\mathrm{TNBC}$ cell lines revealed that enzalutamide enhanced the induction of G1 arrest by palbociclib, indicating that this combination therapy may be effective in TNBC with high AR expression and wild-type $\mathrm{Rb} .{ }^{77} \mathrm{Ji}$ et al found that blocking AR could overcome resistance to $\mathrm{CDK} 4 / 6$ inhibitors, demonstrating that this combination could also be effective in TNBC with impaired $\mathrm{Rb}$ expression. ${ }^{78}$ However, the mechanism of interaction between $\mathrm{Rb}$ and $\mathrm{AR}$ is unclear, so more studies are required in this area. Cumulative preclinical evidence suggests that $\mathrm{AR}+/ \mathrm{Rb}+$ may be a potential biomarker for predicting sensitivity to $\mathrm{CDK} 4 / 6$ inhibitors.

\section{CDK 4/6 Inhibitors in Combination with \\ Phosphoinositide 3-Kinase (PI3K)/Protein Kinase $B$ (AKT)/Rapamycin (mTOR) Inhibition}

The CDK4/6 pathway is involved in a number of important mitotic signaling pathways, providing a strong theoretical basis for CDK4/6 inhibitors combined with other targeted drugs to treat cancer. One such pathway is the $\mathrm{PI} 3 \mathrm{~K} / \mathrm{AKT} / \mathrm{mTOR}$ (PAM) pathway, which regulates cellular functions including proliferation and metabolism and has a key role in the initiation of tumorigenesis. This pathway consists of growth factors and cytokines. In addition to receptor tyrosine kinase (RTK), phosphorylation in this pathway is also carried out by epidermal growth factor receptor (EGFR) and HER2. ${ }^{79}$

The PI3Ks are heterodimers of the subunit $\mathrm{p} 110$, which induce PtdIns $(4,5)$ P2 transition to PtdIns $(3,4,5)$ P3 via the action of 3 '-inositol phosphatase. PI3Ks are grouped into three distinct classes according to structure and function. Three mammalian genes (PIK3CA, PIK3CB, and $P I K 3 C D)$ encode specific catalytic isoforms, p110 $\alpha$, $\mathrm{p} 110 \beta$, and $\mathrm{p} 110 \delta .^{80,81} \mathrm{p} 110 \alpha$ plays important part in the initiation of tumorigenesis owing to an activating mutation in the PIK3CA gene. p110 $\beta$, which phosphorylates PIP3 to 
PIP2 and activates the PI3K-dependent signal, plays a role in phosphatase and tensin Homolog deleted on Chromosome 10 (PTEN)-deficient cancers. PTEN is a known tumor suppressor that is prone to mutations that render it inactive in human cancers. ${ }^{82}$

AKT is phosphorylated via two pathways: in the first, active phosphatidylinositol (3,4,5)-trisphosphate (PIP3) associates with phosphoinositide-dependent kinase-1 (PDK1) to phosphorylate AKT, and in the second, mammalian target of rapamycin complex 2 (mTORC2) phosphorylates AKT completely at Ser473. ${ }^{83}$ The tumor suppressor PTEN and inositol polyphosphate 4-phosphatase type II (INPP4B) can inhibit AKT activity by dephosphorylating PIP2 and PIP3. ${ }^{84}$

mTOR can be activated by phosphorylated eukaryotic initiation factor 4E-binding protein 1 (4E-BP1) and p70S6 kinase (p70S6k) to regulate protein synthesis and cell proliferation. ${ }^{84,85}$ Activating mutations in PIK3CA or $A K T$ in tumor cells triggers the activation of $\mathrm{PI} 3 \mathrm{~K}$ pathway, increasing cyclin D1 levels. ${ }^{86,87}$ Cyclin D-CDK4/6 complexes then stimulate signaling by mTORC 1 , which is located downstream of PI3K (Figure 1). ${ }^{87,88}$

CDK4/6 inhibitors in combination with receptor tyrosine kinase (RTK)-PI3K-AKT signaling pathway inhibitors have been shown to exhibit synergistic effects, and efficacy of the treatment strategies has been demonstrated in a variety of preclinical tumor models, including PI3K inhibitors in breast cancer ${ }^{89}$ and mTOR inhibitors in breast or head and neck cancer. ${ }^{90,91}$

MSL breast cancer accounts for approximately 30\% of TNBC; in this subtype dysregulation of the PI3K/AKT/ mTOR pathway frequently occurs. ${ }^{4,92}$ In the following sections, we discuss different therapeutic strategies, including the CDK4/6 in combination with PI3K inhibitors and AKT inhibitors.

\section{Combination Therapy with CDK4/6 and PI3K Inhibitors}

Genetic changes such as activating PIK3CA mutations often occur in breast cancer; this mutation occurs in up to $25 \%$ of TNBCs. ${ }^{93,94}$ Preclinical research has demonstrated that PI3K inhibitors and CDK4/6 inhibitor have a synergistic effect on the proliferation of multiple PIK3CA mutant cells. ${ }^{53,89}$ Specifically, recent studies suggest that PI3K inhibitors in combination with palbociclib have significant anti-tumor effects by impairing glucose metabolism. ${ }^{14}$ As we all know, stress-activated-protein kinase interacting protein 1 ( $\operatorname{Sin} 1$ ) is the specific component for the mTORC2 kinase complex. $\mathrm{pRb}$ binds to stress-activated protein kinase interacting protein 1 (Sin 1$)$ to inhibit mTORC2 activity. Palbociclib activates AKT by releasing the inhibition of $\mathrm{pRb}$-mediated suppression of mTORC2. When CDK4/6 inhibitors suppress Rb phosphorylation, AKT is activated (Figure 1). ${ }^{95}$ In an in vivo study using HCC1806 and MDAMB231 xenograft models, PI3K inhibitors and palbociclib combination treatment significantly blocked cell cycle progression, immune modulation and DNA damage by increasing tumor-infiltrating T-cell activation. Meanwhile, a TNBC patient-derived xenograft model showed similar tumor growth inhibition. $^{96}$ Existing evidence therefore provides a rationale for clinical trials of this therapeutic combination.

Combination Therapy with CDK4/6 and mTOR Inhibitors mTOR signaling is influenced by growth factor signals and cellular amino acid and energy states, and can regulate cell growth, metabolism, autophagy, and cell cycle progression, making it a promising therapeutic target for TNBC.

mTOR is made up of two different protein complexes: mTORC1 and mTORC2. mTORC1 can regulate cell growth signals, forming a negative feedback loop. Selective inhibition of mTORC1 results in an absence of a negative feedback loop, which may activate mTORC2. According to a recent study, the mTOR inhibitors MLN0128 prevent the proliferation of TNBC cell lines with $\mathrm{Rb}+$ in vitro, as well as in a pRb-expressing TNBC patient-derived xenograft (PDX) model in vivo. MLN0128 is a second-generation dual mTOR kinase inhibitor, which inhibits both mTORC1 and mTORC2. ${ }^{97}$ Results so far suggest that combining this inhibitor with CDK4/6 inhibition may have a strong synergistic inhibitory effect in $\mathrm{RB}+$ TNBC, and therefore merits further study in clinical practice.

\section{Combination Therapy with CDK4/6 and AKT Inhibitors}

AKT is a serine/threonine kinase that can be phosphorylated by a variety of growth signaling molecules; the biochemical mechanisms for which have come to light in recent years. Phosphorylated AKT regulates the function of many proteins, including those involved in cell proliferation, metabolism, migration, and cell cycle, making it a key node in many signaling pathways. ${ }^{98}$ Importantly, AKT can activate CDK2 to induce cell-cycle progression (Figure 1). ${ }^{56}$ Previous studies suggested that PTEN deficiency reduces sensitivity to $\mathrm{PI} 3 \mathrm{~K} \alpha$ inhibition and increases resistance to $\mathrm{CDK} 4 / 6$ inhibitors owing to 
continuous phosphorylation of $\mathrm{Rb}$ and the prevention of cell cycle arrest; however, recently Costa et al found that CDK4/6 inhibitors in combination with AKT inhibition can reverse this resistance. Loss of PTEN expression increases the level of phosphorylated AKT, which can induce delocalization of p27 out of the nucleus and increase the activity of CDK2 and CDK4/6. This process acts to overcome cell cycle arrest in the G1 Phase Induced by CDK4/6 inhibitors. ${ }^{99} \mathrm{CDK} 4 / 6$ inhibition results in the accumulation of cyclin D1, which can then activate CDK2. However, this study was conducted in LAR rather than TNBC subtype of breast cancer, so its applicability to TNBC is unclear. The incidence of PTEN deficiency in breast cancer is similar to the reported incidence of activating $P I 3 K C A$ mutations (7-40\%), and often occurs in TNBC patients; ${ }^{100-102}$ This frequent loss of PTEN may provide a warrant for the exploration of this therapeutic combination in TNBC.

\section{Combination Therapy with CDK4/6 and Immune-Checkpoint Inhibitors}

Regulatory $\mathrm{T}$ (Tregs) cells are a subset of lymphocytes that suppress the proliferation of effector $T$ cells and can facilitate immune evasion in some tumors. ${ }^{103} \mathrm{CDK} 4 / 6$ inhibitors suppress the proliferation of Treg cells stimulated by over-expression of $\mathrm{p} 21$ and reduce E2F target gene DNA methyltransferase (DNMT1) activity. ${ }^{104,105}$ Tumor cells that present antigens via the major histocompatibility complex (MHC) are recognized by cytotoxic $\mathrm{T}$ lymphocytes (CTLs); Tregs inhibit the CTL response, partly by promoting depletion of these immune cells (Figure 1). ${ }^{106}$ CTLs kill tumor cells in the body, increasing the addition of immune-checkpoint blockade. Studies have showed that the efficacy of antitumor immunity via immunogenicity and immune-checkpoint blockade can enhance $T$ cell cytotoxicity. Combination with immune-checkpoint blockade resulted in significantly better overall survival compared to those treated with monotherapy. ${ }^{96}$

Patients with TNBC usually have more tumorinfiltrating lymphocytes (TILs) and higher expression level of the PD-L1 protein. ${ }^{105}$ Higher infiltration of TILs is usually related to poor prognosis, and levels of PD-L1 expression are related to the greater expression of the proliferation marker $\mathrm{Ki}-67$, and the presence of TILs. According to TCGA, the expression of PD-L1 mRNA in TNBC is higher than that in other breast cancer subtypes. Inhibition of CDK4/6 can in turn suppress cyclin D-CDK4 mediated speckle POZ (pox virus and zinc finger protein) protein phosphorylation, improving protein stability of PD-L1; this result has been confirmed in vitro and in xenograft tumors (MDAMB231 PD-L1 wild-type or knockout). These studies indicate that the stability of the PD-L1 protein is regulated by cyclin-dependent kinases, suggesting that clinical the combining of CDK4/6 inhibitors and immune-checkpoint inhibitors may be an effective treatment strategy. ${ }^{107}$

\section{Combination Therapy with CDK4/6 Inhibitors and Anti-EGFR Antibodies}

TNBCs that belong to the basal-like subtype may have EGFR overexpression. It has been reported that EGFR is present in up to $60 \%$ of all TNBCs, but previous clinical trials of anti-EGFR inhibitors as a monotherapy have failed to show improved clinical efficacy, thus reducing interest in using EGFR as a therapeutic agent. ${ }^{108,109}$ Specifically, clinical studies of anti-EGFR antibodies demonstrated no significant increase in progression-free survival in people with TNBC. These disappointing results of anti-EGFR antibodies are in part due to the compensatory tyrosine kinase (TK) signaling pathway and/or unknown factors that interfere with the EGFR pathway. By exploring the markers in populations that would benefit from targeting EGFR and CDK4/6 combination therapy, it paves the way for future clinical trials of individualized drug therapy for TNBC.

Combination Therapy with CDK4/6 Inhibitors and Erlotinib

Matrix metalloproteinase (MMP) is involved in tumor metastasis. Membrane-type-4 (MT4) MMP is a key mediator of the ability of tumor cells to breakthrough the basement membrane and grow in three-dimensional collagen fibers. Approximately $80 \%$ of people with TNBC coexpressed MT4-MMP and EGFR. ${ }^{110,111}$ MT4-MMP is a copolymer of EGFR, and can promote its activation, thereby increasing cyclin and CDK activity and enhancing $\mathrm{Rb}$ phosphorylation. Previous studies showed that MT4MMP expression can stimulate tumor cell proliferation, angiogenesis, and lung metastases by increasing CDK4 activity, promoting $\mathrm{Rb}$ phosphorylation in $3 \mathrm{D}$ culture, and in vivo using a MDAMB231-derived xenograft mouse model. ${ }^{111,112}$ One study suggests that the coexpression of $\mathrm{MT} 4-\mathrm{MMP} / \mathrm{EGFR} / \mathrm{Rb}$ may predict the response of TNBC patients to combination treatment; this study revealed that palbociclib reversed erlotinib resistance in TNBC patients expressing EGFR. This 
combination has demonstrated therapeutic effects in TNBC tumors expressing MT4-MMP, EGFR, and Rb. These findings may help to identify subgroups of patients who may respond to anti-EGFR inhibitors. The expression status of MT4-MMP, EGFR, and Rb is worth considering when selecting patients suitable for combination therapies. $^{113}$

\section{CDK4/6 Inhibitors Plus Lapatinib as a Therapeutic Strategy} in People with EGFR and DEDD Overexpression

Death effector domain-containing protein (DEDD) is significantly upregulated in $60 \%$ of TNBC tumors and is primarily located in the cytoplasm. ${ }^{114}$ In a recent study, lapatinib was shown to transiently inhibit pAKT, but TNBC cells have other alternative mechanisms for maintaining AKT signal. DEDD interacts with heat shock cognate 70 (HSC70) to maintain the expression of cyclin D1 and promote the degradation of $\mathrm{Rb}$ family proteins (Figure 1). Cytosolic over-expression of DEDD contributes to mitogen-independent G1 to $\mathrm{S}$ transition. CDK4/6 inhibitors in combination with lapatinib have been shown to significantly inhibit the proliferation of TNBC cells that overexpress DEDD; blocking the GFR/HER2 signaling pathway and cell cycle transition successfully attenuates TNBC tumor progression. DEDD upregulation in EGFR+ TNBC may provide a rationale for further exploration of this combination treatment in TNBC. ${ }^{115}$

\section{CDK4/6 Inhibitors in Combination with Chemotherapy}

Due to the lack of specific drug targets, chemotherapy, including those with taxanes and anthracyclines, remains the standard treatment in TNBC patients. ${ }^{116}$ However, chemotherapy-induced myelosuppression severely limits its clinical use and efficacy. ${ }^{117}$ Untargeted chemotherapy can induce apoptosis of normal lymphocytes as well as tumor cells, resulting in reduced autoimmune system function. The protection of immune cells from cytotoxic damage caused by chemotherapy drugs could reduce the toxicity of chemotherapy, thus broadening the clinical application of chemotherapy drugs. The proliferation of both hematopoietic stem progenitor cells and lymphocytes depends on the activity of CDK4/6. ${ }^{118}$ Trilaciclib, an intravenous and competitive CDK4/6 inhibitor, has been shown to reduce the myelotoxicity of chemotherapeutic agents by inducing transient cell cycle arrest. This drug can differentially inhibit both cytotoxic and regulatory $\mathrm{T}$ cells. When administered before chemotherapy, the activity of cytotoxic $\mathrm{T}$ lymphocytes can recover quickly, indicating that these cells are protected from cytotoxic damage. ${ }^{119,120}$ Clinical trials are currently underway, but these preliminary results are encouraging. ${ }^{121}$

All genotoxic agents induce DNA damage to promote cell death, which can be repaired via two pathways: homologous recombination (HR) and non-homologous end joining (NHEJ). A previous study demonstrated that simultaneous palbociclib and paclitaxel treatment has an antagonistic effect on antitumor. ${ }^{122}$ The activity of rad51, a critical component of the HR pathway, is repressed in the presence of CDK4/6 inhibitors, resulting in a significant decrease in HR activity; ${ }^{123}$ the burden of DNA repair was found to shift from HR to NHRJ pathway, which is not affected by $\mathrm{Rb}$ and $\mathrm{CDK} 4 / 6$ inhibitors. The mechanism of DNA repair modification may therefore have a significant impact on cells treated with CDK4/6 inhibitors and genotoxic drugs. ${ }^{118}$ However, recent research revealed that when PD0332991 is treated prior to chemotherapy, there is an additional inhibition of cell proliferation, accompanied by a significant increase in apoptosis. The palbociclib/paclitaxel sequential therapy suppresses Palbociclib-mediated induction of AKT and downregulates expression of c-myc, a target gene of E2F, thereby reducing the hypoxiainducible factor subunit $1 \alpha(\mathrm{HIF}-1 \alpha)$ and glucose transporter 1 (GLUT-1) expression, decreasing glucose uptake and consumption. $^{122}$ These results indicate that palbociclibinduced G1 blockade may protect breast cancer cells against cell death induced by paclitaxel when administered simultaneously, but intermittent administration had synergistic effect on killing tumor cells. Clinical trials of PD0332991 in combination with paclitaxel are currently underway in people with advanced breast cancer.

\section{Clinical Trials}

Currently, various randomized clinical trials are currently underway in people with TNBC to identify more specific treatments for this disease. Tables 2 and 3 summarize current randomized trials evaluating the efficacy of CDK4/6 inhibitors in this population in which results are pending and available, respectively.

Notably, early results from Phase I clinical trials reveal that PD0332991 is generally well tolerated with few side effects. ${ }^{124}$ A phase I/II study of this drug in combination with paclitaxel in 27 people with $\mathrm{Rb}$-expressing metastatic breast cancer has been completed (Clinical Trials.gov identifier: NCT01320592). Preliminary results show that alternating sequential palbociclib/paclitaxel treatment is 
Table 2 Ongoing Randomized Phase II/III Clinical Trials CDK4/6 Inhibitors in Triple-Negative Breast Cancer

\begin{tabular}{|c|c|c|c|c|c|c|}
\hline $\begin{array}{l}\text { Clinical } \\
\text { Trials }\end{array}$ & Phase & Allocation & $\begin{array}{l}\text { Study } \\
\text { Population }\end{array}$ & Number & Arms & Primary Endpoint \\
\hline NCT0436094I & $\mathrm{Ib}$ & N/A & $A R+; T N B C$ & 45 & Palbociclib+Avelumab & ORR \\
\hline NCT03090I65 & I/II & N/A & $A R+; T N B C$ & 11 & Ribociclib+Bicalutamide & MTD; CBR \\
\hline NCT03805399 & $\mathrm{I} / \mathrm{II}$ & $\begin{array}{l}\text { Non- } \\
\text { randomized }\end{array}$ & TNBC & 140 & SHR 6390+SHR 3680 & ORR \\
\hline NCT029787I6 & II & Randomized & TNBC & 102 & $\begin{array}{l}\text { Trilaciclib+Gemcitabine } \\
+ \text { +Carboplatin }\end{array}$ & $\begin{array}{l}\text { Number of Treatment Related Adverse } \\
\text { Event }\end{array}$ \\
\hline NCT035I9178 & $\mathrm{I} / 2 \mathrm{~A}$ & $\begin{array}{l}\text { Non- } \\
\text { randomized }\end{array}$ & TNBC & 220 & PF-06873600 & $\begin{array}{l}\text { Number of patients with does limiting } \\
\text { toxicities; Safety and tolerability }\end{array}$ \\
\hline NCT03756090 & & Randomized & TNBC & 100 & $\begin{array}{l}\text { Palbociclib+Dose-dense } \\
\text { neoadjuvant chemotherapy }\end{array}$ & $\mathrm{pCR}$ \\
\hline NCT03।30439 & II & $\mathrm{N} / \mathrm{A}$ & $\mathrm{mTNBC}$ & 37 & Abemaciclib & ORR \\
\hline NCT02605486 & $\mathrm{I} / \mathrm{II}$ & N/A & AR+; TNBC & & Palbociclib+Bicalutamide & $\begin{array}{l}\text { Recommended phase II dose (RP2D) } \\
\text { (phase I); PFS (phase II) }\end{array}$ \\
\hline NCT03979508 & & N/A & TNBC & 100 & Abemaciclib & $\begin{array}{l}\text { Proportion of patients who have a CD8/ } \\
\text { FOXP3 ratio }<1.6\end{array}$ \\
\hline NCT0I 320592 & & N/A & mTNBC & 9 & Palbociclib+Paclitaxel & Adverse Events of PD033299I \\
\hline
\end{tabular}

Abbreviations: TNBC, triple-negative breast cancer; AR, androgen receptor; mTNBC, metastatic triple-negative breast cancer; ORR, objective response rate; MTD, maximum tolerated dose; CBR, clinical benefit rate; PCR, pathological complete response; SHR 6390, cyclin-dependent kinase inhibitor; PF-06873600, Cyclin-dependent kinase inhibitor; SHR3680, androgen receptor inhibitor.

feasible and safe, with no evidence of additive toxicity. ${ }^{125}$ A follow-up trial utilizing imaging biomarkers in people with TNBC is ongoing, which aims to identify which patients benefit from the combination therapies including CDK4/6 inhibitors (ClinicalTrials.gov identifier: NCT02599363). Ultimately, we expect a larger range of randomized clinical trials to evaluate whether this treatment could ultimately improve survival rates in women with advanced breast cancer.

Another current trial aims to assess the clinical efficacy and safety profile of palbociclib in combination with epirubicin and cyclophosphamide followed by paclitaxel as a neoadjuvant therapy (ClinicalTrials.gov identifier: NCT03756090). Whether CDK4/6 inhibitors could be effective in TNBC patients will become clearer as results from further clinical trials are published. One study has reached its prespecified endpoint, with progression-free survival in 11/33 patients at 6 months without any unexpected toxic effects (ClinicalTrials.gov identifier: NCT02605486). ${ }^{126}$ Another study investigating this therapeutic combination also showed preliminary evidence of no dose-limiting toxic effects (ClinicalTrials.gov identifier:
NCT03090165). ${ }^{127}$ In another study, Jiang et al screened specifically enrolled people with TNBC who had wild-type $\mathrm{Rb}$ or AR-positive. However, the results are not very encouraging and only one of the eight patients enrolled in this trial presented with stable disease (SD) (ClinicalTrials. gov identifier: NCT03805399). ${ }^{128}$ Recent data from a Phase II study of trilaciclib combined with chemotherapy, gemcitabine/carboplatin (GC regimen), for the treatment of recurrent or metastatic TNBC demonstrate that trilaciclib therapy administered prior to the GC regimen significantly improved overall survival. The patients were randomly divided into three groups: GC regime alone, Trilaciclib (G1T28)+Gemcitabine/Carboplatin (G1T28 prior to GC on days 1 and 8 in 21-day cycles), Trilaciclib (G1T28) +Gemcitabine/Carboplatin Trilaciclib (G1T28) on Days 1, 2, 8 and 9. GC chemotherapy on Days 2 and 9 in 21-day cycle. Duration of administration also contributed to the difference in overall survival. The results demonstrated that the overall survival is improved from 12.6 months to 20.1 or 17.8 months (ClinicalTrials.gov identifier: NCT02978716). ${ }^{121}$ Based on these encouraging results, a critical study of trilaciclib in TNBC is expected to begin 
Table 3 Available and Published Data on Clinical Trials of CDK4/6 Inhibitors in Triple-Negative Breast Cancer

\begin{tabular}{|c|c|c|c|c|c|}
\hline $\begin{array}{l}\text { Clinical } \\
\text { Trials }\end{array}$ & Phase & Regimens & Patients & Efficacy & Status \\
\hline NCT02605486 & $\mathrm{I} / \mathrm{II}$ & Bicalutamide+ Palbociclib & $\begin{array}{l}\text { AR+ mTNBC } \\
33 p t s\end{array}$ & $\begin{array}{l}\text { Best response: II pts } \\
\text { ( } 3 \text { I evaluable pts) } \\
\text { IO SD }>6 \text { months } \\
\text { IPR } \\
\text { No unexpected } \\
\text { toxicity }\end{array}$ & $\begin{array}{l}\text { Active, not } \\
\text { recruiting }\end{array}$ \\
\hline NCT029787I6 & II & $\begin{array}{l}\text { Group I: GC chemotherapy } \\
\text { Group2: Trilaciclib (GIT28) + Gemcitabine/Carboplatin } \\
\text { (GIT28 prior to GC on days I and } 8 \text { in 2I-day cycles) } \\
\text { Group3: Trilaciclib (GIT28) + Gemcitabine/Carboplatin } \\
\text { Trilaciclib (GIT28) on Days I, } 2,8 \text { and 9. GC } \\
\text { chemotherapy on Days } 2 \text { and } 9 \text { in } 21 \text {-day cycle. }\end{array}$ & $\begin{array}{l}\text { mTNBC } \\
\text { Group I: } 34 \text { pts } \\
\text { Group 2: } 33 \text { pts } \\
\text { Group 3: } 35 \text { pts }\end{array}$ & $\begin{array}{l}\text { Mean duration of } \\
\text { severe neutropenia: } \\
0.8 \text { vs } 1.5 \text { vs } 1.0 \text { days } \\
\text { Severe neutropenia: } \\
26 \% \text { vs } 36 \% \text { vs } 23 \% \\
\text { Os: } 12.6 \text { vs } 20.1 \text { vs } \\
17.8 \text { months }\end{array}$ & $\begin{array}{l}\text { Active, not } \\
\text { recruiting }\end{array}$ \\
\hline NCT03090I65 & 1 & $\begin{array}{l}\text { Group I: B I } 50 \mathrm{mg} / \mathrm{d}(\mathrm{dl}-\mathrm{d} 28)+400 \mathrm{mg} / \mathrm{d}(\mathrm{dI}-\mathrm{d} 2 \mathrm{I}) \\
\text { Group 2: B I50mg/d(d I-d28) }+400 \mathrm{mg} / \mathrm{d}(\mathrm{dI}-\mathrm{d} 28) \\
\text { Group 3: B I50mg/d (dI-d28) }+600 \mathrm{mg} / \mathrm{d}(\mathrm{dI}-\mathrm{d} 2 \mathrm{I})\end{array}$ & $\begin{array}{l}\text { AR+ TNBC } \\
\text { Group I: } 3 \text { pts } \\
\text { Group 2: } 3 \text { pts }\end{array}$ & $\begin{array}{l}\text { Group I and 2: } \\
\text { No dose-limiting } \\
\text { toxicities }\end{array}$ & $\begin{array}{l}\text { Active, not } \\
\text { recruiting }\end{array}$ \\
\hline NCT03805399 & $\mathrm{lb} / \mathrm{ll}$ & AR inhibitor + CDK4/6 inhibitor & $\begin{array}{l}\text { AR+TNBC } \\
\text { I4 pts ( } 8 \\
\text { assessable pts) }\end{array}$ & $\begin{array}{l}\text { I SD; } \\
7 \text { PD }\end{array}$ & Recruiting \\
\hline NCTOI 320592 & I & PD033299I + Paclitaxel & $\begin{array}{l}\mathrm{Rb}+\mathrm{mBC} \\
27 \text { pts (9 TNBC) }\end{array}$ & $\begin{array}{l}\text { NTP (neutropenia): } \\
\text { I5\%; } \\
\text { Grade I or } 2 \text { nausea } \\
\text { and peripheral } \\
\text { neuropathy: } 29.6 \% \text {; } \\
\text { Clinical benefit rate: } \\
55 \% \text { at the RP2D; } \\
\text { No additive toxicity }\end{array}$ & Completed \\
\hline
\end{tabular}

Abbreviations: TNBC, triple-negative breast cancer; AR, androgen receptor; mTNBC, metastatic triple-negative breast cancer; mBC, metastatic triple-negative breast cancer; pts, patients; SD, stable disease; PR, partial response; PD, progressive disease; RP2D, recommended phase II dose.

soon (ClinicalTrials.gov identifier: NCT04799249). However, results from these trials are still pending; the efficacy of the combination therapies outlined in this review must be verified in further clinical trials.

\section{Conclusion}

Clinical indications for CDK4/6 inhibitors are expected to expand over the next few years, changing the treatment landscape for breast cancer. Importantly, CDK4/6 inhibitors in combination with hormonal therapy have been successful as a standard first-line treatment for patients with ER+ breast cancer in pre- and postmenopausal women. Before the CDK4/6 inhibitors can be used in TNBC, two main issues must be addressed: first, acquired drug resistance in those who receive the drug, and secondly, the lack of predictable biomarkers to determine who might benefit from the treatment. Preclinical studies have indicated that CDK4/6 inhibitors may improve the efficacy of other drugs, especially chemotherapy, which remains the standard treatment for this subtype of breast cancer, due to its extremely aggressive nature and lack of established molecular targets for therapy. Genetic mutations also confer tumor cell resistance to $\mathrm{CDK} 4 / 6$ inhibitors, including mutations in TP53 and MYC. Further research is needed to identify additional potential targets that could predict the efficacy of CDK4/6 inhibitors in TNBC. A critical challenge is to integrate the current research-based understanding of TNBC into the design of new clinical trials. Given the ongoing improvements in the recognition and 
understanding of biomarkers and drug resistance targets for CDK4/6 inhibitors in breast cancer, further studies are needed to fully investigate how these therapies could be integrated to improve treatment strategies and outcomes for patients with TNBC.

\section{Acknowledgments}

This work was supported by the National Natural Science Foundation of China (No. 81872156 to Man Li).

\section{Disclosure}

The authors declare that they have no competing interests.

\section{References}

1. Sung H, Ferlay J, Siegel RL, et al. Global cancer statistics 2020: GLOBOCAN estimates of incidence and mortality worldwide for 36 cancers in 185 countries. CA Cancer J Clin. 2021;71 (3):209-249. doi:10.3322/caac.21660

2. Parise CA, Caggiano V. Breast cancer survival defined by the ER/ PR/HER2 subtypes and a surrogate classification according to tumor grade and immunohistochemical biomarkers. $J$ Cancer Epidemiol. 2014;2014:1-11. doi:10.1155/2014/469251

3. Bianchini G, Balko JM, Mayer IA, Sanders ME, Gianni L. Triplenegative breast cancer: challenges and opportunities of a heterogeneous disease. Nat Rev Clin Oncol. 2016;13:674-690. doi:10.1038/nrclinonc.2016.66

4. Lehmann BD, Bauer JA, Chen X, et al. Identification of human triple-negative breast cancer subtypes and preclinical models for selection of targeted therapies. $J$ Clin Invest. 2011;121:2750-2767. doi:10.1172/JCI45014

5. Jiang YZ, Ma D, Suo C, et al. Genomic and transcriptomic landscape of triple-negative breast cancers: subtypes and treatment strategies. Cancer Cell. 2019;35:428-440. doi:10.1016/j. ccell.2019.02.001

6. Li Y, Rogoff HA, Keates S, et al. Suppression of cancer relapse and metastasis by inhibiting cancer stemness. Proc Natl Acad Sci USA. 2015;112:1839-1844. doi:10.1073/pnas.1424171112

7. Robson M, Im SA, Senkus E, et al. Olaparib for metastatic breast cancer in patients with a germline BRCA mutation. $N$ Engl $J$ Med. 2017;377:523-533. doi:10.1056/NEJMoa1706450

8. Schmid P, Adams S, Rugo HS, et al. Atezolizumab and nab-paclitaxel in advanced triple-negative breast cancer. $N$ Engl J Med. 2018;379:2108-2121. doi:10.1056/NEJMoa1809615

9. Heimes AS, Schmidt M. Atezolizumab for the treatment of triple-negative breast cancer. Expert Opin Investig Drugs. 2019;28:1-5. doi:10.1080/13543784.2019.1552255

10. Romero D. Benefit in patients with PD-L1-positive TNBC. Nat Rev Clin Oncol. 2019;16:6.

11. Hanahan D, Weinberg RA. Hallmarks of cancer: the next generation. Cell. 2011;144:646-674. doi:10.1016/j.cell.2011.02.013

12. Arnold A, Papanikolaou A. Cyclin D1 in breast cancer pathogenesis. J Clin Oncol. 2005;23:4215-4224. doi:10.1200/JCO.2005.05.064

13. Yu Q, Geng Y, Sicinski P. Specific protection against breast cancers by cyclin D1 ablation. Nature. 2001;411:1017-1021. doi: $10.1038 / 35082500$

14. Cretella D, Ravelli A, Fumarola C, et al. The anti-tumor efficacy of CDK4/6 inhibition is enhanced by the combination with PI3K/ AKT/mTOR inhibitors through impairment of glucose metabolism in TNBC cells. J Exp Clin Cancer Res. 2018;37. doi:10.1186/s13046-018-0741-3
15. Clark AS, Karasic TB, DeMichele A, et al. Palbociclib (PD0332991) - a selective and potent cyclin-dependent kinase inhibitor A review of pharmacodynamics and clinical development. JAMA Oncol. 2016;2:253-260. doi:10.1001/jamaoncol.2015.4701

16. Finn RS, Dering J, Conklin D, et al. PD 0332991, a selective cyclin D kinase $4 / 6$ inhibitor, preferentially inhibits proliferation of luminal estrogen receptor-positive human breast cancer cell lines in vitro. Breast Cancer Res. 2009;11:R77. doi:10.1186/bcr2419

17. Ingham M, Schwartz GK. Cell-cycle therapeutics come of age. J Clin Oncol. 2017;35:2949-2959. doi:10.1200/JCO.2016.69.0032

18. Deshpande A, Sicinski P, Hinds PW. Cyclins and cdks in development and cancer: a perspective. Oncogene. 2005;24:2909-2915. doi:10.1038/sj.onc.1208618

19. Hochegger H, Takeda S, Hunt T. Cyclin-dependent kinases and cell-cycle transitions: does one fit all. Nat Rev Mol Cell Biol. 2008;9:910-916. doi:10.1038/nrm2510

20. Schachter MM, Merrick KA, Larochelle S, et al. A Cdk7-Cdk4 T-loop phosphorylation cascade promotes G1 progression. Mol Cell. 2013;50:250-260. doi:10.1016/j.molcel.2013.04.003

21. Pandey K, An HJ, Kim SK, et al. Molecular mechanisms of resistance to $\mathrm{CDK} 4 / 6$ inhibitors in breast cancer: a review. Int J Cancer. 2019;145:1179-1188. doi:10.1002/ijc.32020

22. Trimarchi JM, Lees JA. Sibling rivalry in the E2F family. Nat Rev Mol Cell Biol. 2002;3:11-20. doi:10.1038/nrm714

23. Massagué J. G1 cell-cycle control and cancer. Nature. 2004;432:298-306. doi:10.1038/nature03094

24. Pardee AB. G1 events and regulation of cell proliferation. Science. 1989;246:603-608. doi:10.1126/science.2683075

25. Matsushime H, Roussel MF, Ashmun RA, Sherr CJ. Colonystimulating factor 1 regulates novel cyclins during the G1 phase of the cell cycle. Cell. 1991;65:701-713. doi:10.1016/00928674(91)90101-4

26. Meyerson M, Harlow E. Identification of G1 kinase activity for cdk6, a novel cyclin D partner. Mol Cell Biol. 1994;14:2077-2086. doi:10.1128/mcb.14.3.2077-2086.1994

27. Canepa ET, Scassa ME, Ceruti JM, et al. INK4 proteins, a family of mammalian CDK inhibitors with novel biological functions. Iubmb Life. 2007;59:419-426. doi:10.1080/15216540701488358

28. Spencer SL, Cappell SD, Tsai F, Overton KW, Wang CL, Meyer T. The proliferation-quiescence decision is controlled by a bifurcation in CDK2 activity at mitotic exit. Cell. 2013;155:369-383. doi:10.1016/j.cell.2013.08.062

29. Gong X, Litchfield LM, Webster Y, et al. Genomic aberrations that activate D-type cyclins are associated with enhanced sensitivity to the CDK4 and CDK6 inhibitor abemaciclib. Cancer Cell. 2017;32:761-776. doi:10.1016/j.ccell.2017.11.006

30. Sherr CJ, Roberts JM. CDK inhibitors: positive and negative regulators of G1-phase progression. Genes Dev. 1999;13:1501-1512. doi:10.1101/gad.13.12.1501

31. Harper JW, Adami GR, Wei N, Keyomarsi K, Elledge SJ. The p21 Cdk-interacting protein Cip1 is a potent inhibitor of G1 cyclin-dependent kinases. Cell. 1993;75:805-816. doi:10.1016/ 0092-8674(93)90499-G

32. Blain SW, Montalvo E, Massague J. Differential interaction of the cyclin-dependent kinase (Cdk) inhibitor p27Kip1 with cyclin A-Cdk2 and cyclin D2-Cdk4. $J$ Biol Chem. 1997;272:25863-25872. doi:10.1074/jbc.272.41.25863

33. Senderowicz AM. Flavopiridol: the first cyclin-dependent kinase inhibitor in human clinical trials. Invest New Drugs. 1999;17:313-320. doi:10.1023/A:1006353008903

34. Shapiro GI. Cyclin-dependent kinase pathways as targets for cancer treatment. $J$ Clin Oncol. 2006;24:1770-1783. doi:10.1200/JCO.2005.03.7689

35. Konecny GE. Cyclin-dependent kinase pathways as targets for women's cancer treatment. Curr Opin Obstet Gynecol. 2016;28:42-48. doi:10.1097/GCO.0000000000000243 
36. Kouroukis CT, Belch A, Crump M, et al. Flavopiridol in untreated or relapsed mantle-cell lymphoma: results of a phase II study of the National Cancer Institute of Canada Clinical Trials Group. J Clin Oncol. 2003;21:1740-1745. doi:10.1200/JCO.2003.09.057

37. Jessen BA, Lee L, Koudriakova T, et al. Peripheral white blood cell toxicity induced by broad spectrum cyclin-dependent kinase inhibitors. J Appl Toxicol. 2007;27:133-142. doi:10.1002/jat.1177

38. Parry D, Guzi T, Shanahan F, et al. Dinaciclib (SCH 727965), a novel and potent cyclin dependent kinase inhibitor. Mol Cancer Ther. 2010;9:2344-2353. doi:10.1158/1535-7163.MCT-10-0324

39. Fry DW, Harvey PJ, Keller PR, et al. Specific inhibition of cyclin-dependent kinase 4/6 by PD 0332991 and associated antitumor activity in human tumor xenografts. Mol Cancer Ther. 2004;3:1427-1438.

40. Finn RS, Crown JP, Lang I, et al. The cyclin-dependent kinase 4/6 inhibitor palbociclib in combination with letrozole versus letrozole alone as first-line treatment of oestrogen receptor-positive, HER2-negative, advanced breast cancer (PALOMA-1/TRIO-18): a randomised Phase 2 study. Lancet Oncol. 2015;16:25-35. doi:10.1016/S1470-2045(14)71159-3

41. Hortobagyi GN, Stemmer SM, Burris HA, et al. Ribociclib as first-line therapy for HR-positive, advanced breast cancer. $N$ Engl J Med. 2018;379:2582.

42. Dickler MN, Tolaney SM, Rugo HS, et al. MONARCH 1, A Phase II Study of abemaciclib, a CDK4 and CDK6 Inhibitor, as a single agent, in patients with refractory $\mathrm{HR}(+) / \mathrm{HER} 2(-)$ metastatic breast cancer. Clin Cancer Res. 2017;23:5218-5224. doi:10.1158/1078-0432.CCR-17-0754

43. Sledge GJ, Toi M, Neven P, et al. MONARCH 2: abemaciclib in combination with fulvestrant in women with HR+/HER2advanced breast cancer who had progressed while receiving endocrine therapy. J Clin Oncol. 2017;35:2875-2884. doi:10.1200/ JCO.2017.73.7585

44. Finn RS, Martin M, Rugo HS, et al. Palbociclib and letrozole in advanced breast cancer. $N$ Engl J Med. 2016;375:1925-1936. doi:10.1056/NEJMoa1607303

45. Cristofanilli M, Turner NC, Bondarenko I, et al. Fulvestrant plus palbociclib versus fulvestrant plus placebo for treatment of hormone-receptor-positive, HER2-negative metastatic breast cancer that progressed on previous endocrine therapy (PALOMA-3) final analysis of the multicentre, double-blind, Phase 3 randomised controlled trial. Lancet Oncol. 2016;17:425-439. doi:10.1016/S1470-2045(15)00613-0

46. Carey LA, Dees EC, Sawyer L, et al. The triple negative paradox: primary tumor chemosensitivity of breast cancer subtypes. Clin Cancer Res. 2007;13:2329-2334. doi:10.1158/1078-0432.CCR-061109

47. Dent R, Trudeau M, Pritchard KI, et al. Triple-negative breast cancer: clinical features and patterns of recurrence. Clin Cancer Res. 2007;13:4429-4434. doi:10.1158/1078-0432.CCR-06-3045

48. Carey L, Winer E, Viale G, Cameron D, Gianni L. Triple-negative breast cancer: disease entity or title of convenience? Nat Rev Clin Oncol. 2010;7:683-692. doi:10.1038/nrclinonc.2010.154

49. Yin WJ, Lu JS, Di GH, et al. Clinicopathological features of the triple-negative tumors in Chinese breast cancer patients. Breast Cancer Res Treat. 2009;115:325-333. doi:10.1007/s10549-0080096-0

50. Dignam JJ, Dukic V, Anderson SJ, Mamounas EP, Wickerham DL, Wolmark N. Hazard of recurrence and adjuvan treatment effects over time in lymph node-negative breast cancer. Breast Cancer Res Treat. 2009;116:595-602. doi:10.1007/ s10549-008-0200-5

51. Ciriello G, Gatza ML, Beck AH, et al. Comprehensive molecular portraits of human breast tumours. Nature. 2012;490:61-70.
52. An O, Dall'Olio GM, Mourikis TP, Ciccarelli FD. NCG 5.0: updates of a manually curated repository of cancer genes and associated properties from cancer mutational screenings. Nucleic Acids Res. 2016;44:D992-9. doi:10.1093/nar/gkv1123

53. Asghar US, Barr AR, Cutts R, et al. Single-cell dynamics determines response to $\mathrm{CDK} 4 / 6$ inhibition in triple-negative breast cancer. Clin Cancer Res. 2017;23:5561-5572. doi:10.1158/10780432.CCR-17-0369

54. Dean JL, McClendon AK, Hickey TE, et al. Therapeutic response to CDK4/6 inhibition in breast cancer defined by ex vivo analyses of human tumors. Cell Cycle. 2012;11:2756-2761. doi:10.4161/ cc. 21195

55. Condorelli R, Spring L, O’Shaughnessy J, et al. Polyclonal RB1 mutations and acquired resistance to $\mathrm{CDK} 4 / 6$ inhibitors in patients with metastatic breast cancer. Ann Oncol. 2018;29:640-645. doi:10.1093/annonc/mdx784

56. O'Leary B, Finn RS, Turner NC. Treating cancer with selective CDK4/6 inhibitors. Nat Rev Clin Oncol. 2016;13:417-430. doi:10.1038/nrclinonc.2016.26

57. Wiedemeyer WR, Dunn IF, Quayle SN, et al. Pattern of retinoblastoma pathway inactivation dictates response to CDK4/6 inhibition in GBM. Proc Natl Acad Sci $U$ S A. 2010;107:11501-11506. doi:10.1073/pnas.1001613107

58. Witkiewicz AK, Knudsen KE, Dicker AP, Knudsen ES. The meaning of p16(ink4a) expression in tumors: functional significance, clinical associations and future developments. Cell Cycle. 2011;10:2497-2503. doi:10.4161/cc.10.15.16776

59. Tort F, Bartkova J, Sehested M, Orntoft T, Lukas J, Bartek J. Retinoblastoma pathway defects show differential ability to activate the constitutive DNA damage response in human tumorigenesis. Cancer Res. 2006;66:10258-10263. doi:10.1158/ 0008-5472.CAN-06-2178

60. Vijayaraghavan S, Karakas C, Doostan I, et al. CDK4/6 and autophagy inhibitors synergistically induce senescence in $\mathrm{Rb}$ positive cytoplasmic cyclin E negative cancers. Nat Commun. 2017;8:15916. doi:10.1038/ncomms15916

61. Rubin SM. Deciphering the retinoblastoma protein phosphorylation code. Trends Biochem Sci. 2013;38:12-19. doi:10.1016/j. tibs.2012.10.007

62. Weintraub SJ, Chow KN, Luo RX, Zhang SH, He S, Dean DC. Mechanism of active transcriptional repression by the retinoblastoma protein. Nature. 1995;375:812-815. doi:10.1038/ $375812 \mathrm{a} 0$

63. Harbour JW, Luo RX, Dei Santi A, Postigo AA, Dean DC. Cdk phosphorylation triggers sequential intramolecular interactions that progressively block $\mathrm{Rb}$ functions as cells move through $\mathrm{G} 1$. Cell. 1999;98:859-869. doi:10.1016/S0092-8674(00)81519-6

64. Hiebert SW, Chellappan SP, Horowitz JM, Nevins JR. The interaction of RB with E2F coincides with an inhibition of the transcriptional activity of E2F. Genes Dev. 1992;6:177-185. doi:10.1101/gad.6.2.177

65. Brasca MG, Amboldi N, Ballinari D, et al. Identification of N,1,4,4-tetramethyl-8-\{[4-(4-methylpiperazin-1-yl)phenyl] amino $\}$-4,5-dihydro-1H-pyrazolo[4,3-h]quinazoline-3-carboxamide (PHA-848125), a potent, orally available cyclin dependent kinase inhibitor. J Med Chem. 2009;52:5152-5163. doi:10.1021/ jm9006559

66. Glick D, Barth S, Macleod KF. Autophagy: cellular and molecular mechanisms. J Pathol. 2010;221:3-12. doi:10.1002/path.2697

67. Wang R, Zhang Q, Peng X, et al. Stellettin B induces G1 arrest, apoptosis and autophagy in human non-small cell lung cancer A549 cells via blocking PI3K/Akt/mTOR pathway. Sci Rep. 2016;6:27071. doi:10.1038/srep27071 
68. Chittaranjan S, Bortnik S, Dragowska WH, et al. Autophagy inhibition augments the anticancer effects of epirubicin treatment in anthracycline-sensitive and -resistant triple-negative breast cancer. Clin Cancer Res. 2014;20:3159-3173. doi:10.1158/10780432.CCR-13-2060

69. Collins LC, Cole KS, Marotti JD, et al. Androgen receptor expression in breast cancer in relation to molecular phenotype: results from the Nurses' Health Study. Mod Pathol. 2011;24 (7):924-931. doi:10.1038/modpathol.2011.54

70. Gasparini P, Fassan M, Cascione L, et al. Androgen receptor status is a prognostic marker in non-basal triple negative breast cancers and determines novel therapeutic options. PLoS One. 2014;9(2):e88525. doi:10.1371/journal.pone.0088525

71. Safarpour D, Tavassoli AT. A targetable androgen receptor-positive breast cancer subtype hidden among the triple-negative cancers. Arch Pathol Lab Med. 2015;139 (5):612-617. doi:10.5858/arpa.2014-0122-RA

72. Mrklić L, Pogorelić Z, Capkun V, Tomić S. Expression of androgen receptors in triple negative breast carcinomas. Acta Histochem. 2013;115(4):344-348. doi:10.1016/j.acthis.2012.09.006

73. McNamara KM, Yoda T, Miki Y, et al. Androgenic pathway in triple negative invasive ductal tumors: its correlation with tumor cell proliferation. Cancer Sci. 2013;104(5):639-646. doi:10.1111/ cas. 12121

74. Scher HI, Fizazi K, Saad F, et al. Increased survival with enzalutamide in prostate cancer after chemotherapy. $N$ Engl $J$ Med. 2012;367:1187-1197. doi:10.1056/NEJMoa1207506

75. Beer TM, Armstrong AJ, Rathkopf DE, et al. Enzalutamide in metastatic prostate cancer before chemotherapy. $N$ Engl $J$ Med. 2014;371:424-433. doi:10.1056/NEJMoa1405095

76. Doane AS, Danso M, Lal P, et al. An estrogen receptor-negative breast cancer subset characterized by a hormonally regulated transcriptional program and response to androgen. Oncogene. 2006;25:3994-4008. doi:10.1038/sj.onc.1209415

77. Liu CY, Lau KY, Hsu CC, et al. Combination of palbociclib with enzalutamide shows in vitro activity in RB proficient and androgen receptor positive triple negative breast cancer cells. PLoS One. 2017;12:e189007. doi:10.1371/journal.pone.0189007

78. Ji W, Shi Y, Wang X, et al. Combined androgen receptor blockade overcomes the resistance of breast cancer cells to palbociclib. Int J Biol Sci. 2019;15:522-532. doi:10.7150/ijbs.30572

79. Pawson T, Nash P. Assembly of cell regulatory systems through protein interaction domains. Science. 2003;300:445-452. doi:10.1126/science. 1083653

80. Lannutti BJ, Meadows SA, Herman SE, et al. CAL-101, a p110delta selective phosphatidylinositol-3-kinase inhibitor for the treatment of B-cell malignancies, inhibits PI3K signaling and cellular viability. Blood. 2011;117:591-594. doi:10.1182/blood2010-03-275305

81. Engelman JA, Luo J, Cantley LC. The evolution of phosphatidylinositol 3-kinases as regulators of growth and metabolism. Nat Rev Genet. 2006;7:606-619. doi:10.1038/nrg1879

82. Salmena L, Carracedo A, Pandolfi PP. Tenets of PTEN tumor suppression. Cell. 2008;133:403-414. doi:10.1016/j. cell.2008.04.013

83. Hill MM, Hemmings BA. Inhibition of protein kinase B/Akt. implications for cancer therapy. Pharmacol Ther. 2002;93:243-251. doi:10.1016/S0163-7258(02)00193-6

84. Zoncu R, Efeyan A, Sabatini DM. mTOR: from growth signal integration to cancer, diabetes and ageing. Nat Rev Mol Cell Biol. 2011;12:21-35. doi:10.1038/nrm3025

85. Nojima H, Tokunaga C, Eguchi S, et al. The mammalian target of rapamycin (mTOR) partner, raptor, binds the mTOR substrates p70 S6 kinase and 4E-BP1 through their TOR signaling (TOS) motif. J Biol Chem. 2003;278:15461-15464. doi:10.1074/jbc. C200665200
86. Diehl JA, Cheng M, Roussel MF, Sherr CJ. Glycogen synthase kinase-3beta regulates cyclin D1 proteolysis and subcellular localization. Genes Dev. 1998;12:3499-3511. doi:10.1101/ gad.12.22.3499

87. Albers MW, Williams RT, Brown EJ, Tanaka A, Hall FL, Schreiber SL. FKBP-rapamycin inhibits a cyclin-dependent kinase activity and a cyclin D1-Cdk association in early G1 of an osteosarcoma cell line. J Biol Chem. 1993;268:22825-22829. doi:10.1016/S0021-9258(18)41602-X

88. Zacharek SJ, Xiong Y, Shumway SD. Negative regulation of TSC1-TSC2 by mammalian D-type cyclins. Cancer Res. 2005;65:11354-11360. doi:10.1158/0008-5472.CAN-05-2236

89. Vora SR, Juric D, Kim N, et al. CDK 4/6 inhibitors sensitize PIK3CA mutant breast cancer to PI3K inhibitors. Cancer Cell. 2014;26:136-149. doi:10.1016/j.ccr.2014.05.020

90. Ku BM, Yi SY, Koh J, et al. The CDK4/6 inhibitor LY2835219 has potent activity in combination with mTOR inhibitor in head and neck squamous cell carcinoma. Oncotarget. 2016;7:14803-14813. doi:10.18632/oncotarget.7543

91. Michaloglou C, Crafter C, Siersbaek R, et al. Combined inhibition of mTOR and CDK4/6 is required for optimal blockade of $\mathrm{E} 2 \mathrm{~F}$ function and long-term growth inhibition in estrogen receptor-positive breast cancer. Mol Cancer Ther. 2018;17:908-920. doi:10.1158/1535-7163.MCT-17-0537

92. Yu KD, Zhu R, Zhan M, et al. Identification of prognosis-relevant subgroups in patients with chemoresistant triple-negative breast cancer. Clin Cancer Res. 2013;19:2723-2733. doi:10.1158/10780432.CCR-12-2986

93. Courtney KD, Corcoran RB, Engelman JA. The PI3K pathway as drug target in human cancer. J Clin Oncol. 2010;28:1075-1083. doi:10.1200/JCO.2009.25.3641

94. Fedele CG, Ooms LM, Ho M, et al. Inositol polyphosphate 4-phosphatase II regulates PI3K/Akt signaling and is lost in human basal-like breast cancers. Proc Natl Acad Sci U S A. 2010;107:22231-22236. doi:10.1073/pnas.1015245107

95. Zhang J, Xu K, Liu P, et al. Inhibition of $\mathrm{Rb}$ phosphorylation leads to mTORC2-mediated activation of Akt. Mol Cell. 2016;62:929-942. doi:10.1016/j.molcel.2016.04.023

96. Teo ZL, Versaci S, Dushyanthen S, et al. Combined CDK4/6 and PI3Kalpha inhibition is synergistic and immunogenic in triple-negative breast cancer. Cancer Res. 2017;77:6340-6352. doi:10.1158/0008-5472.CAN-17-2210

97. Yamamoto T, Kanaya N, Somlo G, Chen S. Synergistic anti-cancer activity of CDK4/6 inhibitor palbociclib and dual mTOR kinase inhibitor MLN0128 in pRb-expressing ER-negative breast cancer. Breast Cancer Res Treat. 2019;174:615-625. doi:10.1007/s10549-018-05104-9

98. Revathidevi S, Munirajan AK. Akt in cancer: mediator and more. Semin Cancer Biol. 2019;59:80-91. doi:10.1016/j. semcancer.2019.06.002

99. Costa C, Wang Y, Ly A, et al. PTEN loss mediates clinical crossresistance to CDK4/6 and PI3K $\alpha$ inhibitors in breast cancer. Cancer Discov. 2020;10(1):72-85. doi:10.1158/2159-8290.CD-18-0830

100. Lopez-Knowles E, O'Toole SA, McNeil CM, et al. PI3K pathway activation in breast cancer is associated with the basal-like phenotype and cancer-specific mortality. Int $J$ Cancer. 2010;126:1121-1131. doi:10.1002/ijc.24831

101. Saal LH, Holm K, Maurer M, et al. PIK3CA mutations correlate with hormone receptors, node metastasis, and ERBB2, and are mutually exclusive with PTEN loss in human breast carcinoma. Cancer Res. 2005;65:2554-2559. doi:10.1158/0008-5472-CAN $-04-3913$

102. Perez-Tenorio G, Alkhori L, Olsson B, et al. PIK3CA mutations and PTEN loss correlate with similar prognostic factors and are not mutually exclusive in breast cancer. Clin Cancer Res. 2007;13:3577-3584. doi:10.1158/1078-0432.CCR-06-1609 
103. Betts G, Twohig J, Van den Broek M, Sierro S, Godkin A, Gallimore A. The impact of regulatory $\mathrm{T}$ cells on carcinogen-induced sarcogenesis. $\mathrm{Br} J$ Cancer. 2007;96:1849-1854. doi:10.1038/sj.bjc.6603824

104. Kimura H, Nakamura T, Ogawa T, Tanaka S, Shiota K. Transcription of mouse DNA methyltransferase 1 (Dnmt1) is regulated by both E2F-Rb-HDAC-dependent and -independent pathways. Nucleic Acids Res. 2003;31:3101-3113. doi:10.1093/ nar/gkg406

105. Goel S, DeCristo MJ, Watt AC, et al. CDK4/6 inhibition triggers anti-tumour immunity. Nature. 2017;548:471-475. doi:10.1038/ nature23465

106. Bauer CA, Kim EY, Marangoni F, Carrizosa E, Claudio NM, Mempel TR. Dynamic Treg interactions with intratumoral APCs promote local CTL dysfunction. $J$ Clin Invest. 2014;124:2425-2440. doi:10.1172/JCI66375

107. Zhang J, Bu X, Wang H, et al. Cyclin D-CDK4 kinase destabilizes PD-L1 via cullin 3-SPOP to control cancer immune surveillance. Nature. 2018;553:91-95. doi:10.1038/nature25015

108. Chabottaux V, Sounni NE, Pennington CJ, et al. Membrane-type 4 matrix metalloproteinase promotes breast cancer growth and metastases. Cancer Res. 2006;66:5165-5172. doi:10.1158/00085472.CAN-05-3012

109. Nielsen TO, Hsu FD, Jensen K, et al. Immunohistochemical and clinical characterization of the basal-like subtype of invasive breast carcinoma. Clin Cancer Res. 2004;10:5367-5374. doi:10.1158/1078-0432.CCR-04-0220

110. Yip C, Foidart P, Somja J, et al. MT4-MMP and EGFR expression levels are key biomarkers for breast cancer patient response to chemotherapy and erlotinib. $B r J$ Cancer. 2017;116:742-751. doi:10.1038/bjc.2017.23

111. Paye A, Truong A, Yip C, et al. EGFR activation and signaling in cancer cells are enhanced by the membrane-bound metalloprotease MT4-MMP. Cancer Res. 2014;74:6758-6770. doi:10.1158/ 0008-5472.CAN-13-2994

112. Host L, Paye A, Detry B, et al. The proteolytic activity of MT4-MMP is required for its pro-angiogenic and pro-metastatic promoting effects. Int $J$ Cancer. 2012;131:1537-1548. doi:10.1002/ijc.27436

113. Foidart P, Yip C, Radermacher J, et al. Expression of MT4-MMP, EGFR, and RB in triple-negative breast cancer strongly sensitizes tumors to erlotinib and palbociclib combination therapy. Clin Cancer Res. 2019;25:1838-1850. doi:10.1158/1078-0432.CCR18-1880

114. Schickling O, Stegh AH, Byrd J, Peter ME. Nuclear localization of DEDD leads to caspase- 6 activation through its death effector domain and inhibition of RNA polymerase I dependent transcription. Cell Death Differ. 2001;8:1157-1168. doi:10.1038/ sj.cdd. 4400928

115. Ni Y, Schmidt KR, Werner BA, et al. Death effector domain-containing protein induces vulnerability to cell cycle inhibition in triple-negative breast cancer. Nat Commun. 2019;10:2869. doi:10.1038/s41467-019-10743-7
116. Beslija S, Bonneterre J, Burstein H, et al. Third Consensus on medical treatment of metastatic breast cancer. Ann Oncol. 2009;20:1771-1785. doi:10.1093/annonc/mdp261

117. Malhotra MK, Emens LA. The evolving management of metastatic triple negative breast cancer. Semin Oncol. 2020;47 (4):229-237. doi:10.1053/j.seminoncol.2020.05.005

118. Dean JL, McClendon AK, Knudsen ES. Modification of the DNA damage response by therapeutic CDK4/6 inhibition. J Biol Chem. 2012;287:29075-29087. doi:10.1074/jbc.M112.365494

119. He S, Roberts PJ, Sorrentino JA, et al. Transient CDK4/6 inhibition protects hematopoietic stem cells from chemotherapy-induced exhaustion. Sci Transl Med. 2017;9(387): eaal3986. doi:10.1126/scitranslmed.aal3986

120. Roskoski R Jr. Cyclin-dependent protein serine/threonine kinase inhibitors as anticancer drugs. Pharmacol Res. 2019;139:471-488. doi:10.1016/j.phrs.2018.11.035

121. Tan AR, Wright GS, Thummala AR, et al. Trilaciclib plus chemotherapy versus chemotherapy alone in patients with metastatic triple-negative breast cancer: a multicentre, randomised, open-label, phase 2 trial. Lancet Oncol. 2019;20(11):1587-1601. doi:10.1016/S1470-2045(19)30616-3

122. Cretella D, Fumarola C, Bonelli M, et al. Pre-treatment with the CDK4/6 inhibitor palbociclib improves the efficacy of paclitaxel in TNBC cells. Sci Rep. 2019;9:13014. doi:10.1038/s41598-01949484-4

123. Sonoda E, Sasaki MS, Buerstedde JM, et al. Rad51-deficient vertebrate cells accumulate chromosomal breaks prior to cell death. EMBO J. 1998;17:598-608. doi:10.1093/emboj/17.2.598

124. Schwartz GK, LoRusso PM, Dickson MA, et al. Phase I study of PD 0332991, a cyclin-dependent kinase inhibitor, administered in 3-week cycles (Schedule 2/1). Br J Cancer. 2011;104:1862-1868. doi: $10.1038 /$ bjc. 2011.177

125. Clark AS, McAndrew NP, Troxel A, et al. Combination paclitaxel and palbociclib: results of a Phase I Trial in advanced breast cancer. Clin Cancer Res. 2019;25(7):2072-2079. doi:10.1158/ 1078-0432.CCR-18-0790

126. Ayca G, Leigh AB, Tina A, et al. Phase II trial of bicalutamide in combination with palbociclib for the treatment of androgen receptor (+) metastatic breast cancer. J Clin Oncol. 2020;15:1017.

127. Sharifi M, Wisinski KB, Burkard ME, et al. Phase I trial of bicalutamide and ribociclib in androgen receptor-positive triple negative breast cancer. Available from: https://www.abstracts2 view.com/sabcs18/view.php?nu=SABCS18L 297. Accessed December 5, 2018 .

128. Jiang YZ, Liu Y, Xiao Y, et al. Molecular subtyping and genomic profiling expand precision medicine in refractory metastatic triple-negative breast cancer: the FUTURE trial. Cell Res. 2021;31(2):178-186. doi:10.1038/s41422-020-0375-9

\section{Publish your work in this journal}

Cancer Management and Research is an international, peer-reviewed open access journal focusing on cancer research and the optimal use of preventative and integrated treatment interventions to achieve improved outcomes, enhanced survival and quality of life for the cancer patient.
The manuscript management system is completely online and includes a very quick and fair peer-review system, which is all easy to use. Visit http://www.dovepress.com/testimonials.php to read real quotes from published authors. 